\title{
The Effect of Situational Variables on Teams' Performance in Offensive Sequences Ending in a Shot on Goal. A Case Study
}

\author{
J. Pratas*, A. Volossovitch and A. P. Ferreira
}

Faculty of Human Kinetics, Technical University of Lisbon, Portugal

\begin{abstract}
The aim of this study is to analyze the effect of quality of opposition and game period, considered independently and interactively, on team performance in offensive sequences ending in a shot on goal by a Portuguese professional association football team. A total of 155 offensive sequences were sampled from ten matches involving a team from the Portuguese Premier League during the 2009-2010 season. The team's offensive performance was examined using notation and time-motion analysis. The observation system, composed of 14 performance indicators, was developed to record the team's offensive performance. Data were collected using Match Vision, TACTO and MATLAB software, and analyzed using descriptive statistical methods, two-way ANOVA and log-linear modeling. The results reveal the significant effect of quality of opposition on game situations in which shots were made $(p \leq 0.05)$, a numerical relationship between attack and defense players $(p \leq 0.05)$ and in the distance covered by players $(p \leq 0.05)$; game period had a significant effect on the length of offensive actions $(\mathrm{p} \leq 0.05)$ and the distance covered by players $(\mathrm{p} \leq 0.05)$. No interactive effect of quality of opposition and game period on offensive performance indicators was found. These findings suggest that team offensive play in sequences ending in a shot on goal are influenced by situational variables. Further research should focus on the independent and interactive effects of match context on the spatial-temporal variables that describe players' offensive and defensive behavior in different stages of a game.
\end{abstract}

Keywords: Contextual variables, soccer, match analysis, team offensive performance, spatial-temporal variables.

\section{INTRODUCTION}

Most studies that analyze team offensive performance have focused on scoring situations and patterns of play leading to a shot on goal [1-3]. However, these situations have often been examined without taking into account the specific characteristics of a given match, which may affect the tactical options available to teams, in terms of both attack and defense [4].

Previous studies have reported the importance of considering situational variables (for example, quality of opposition, match location, match status and game period) in performance assessment in football [5-9]. It has been shown that the performance of football teams varies according to the level of quality of the opponents $[10,11]$ and that teams use different strategies when winning, drawing and losing [4, 9]. Furthermore, it has been demonstrated [12-14] that team performance during some periods of a match may have a greater impact on the outcome of the game.

Several studies have suggested the influence of the quality of opponents, match location and match status on the following performance indicators in elite football: (i) the total number of shots made and received [10]; (ii) strategies of ball possession (analyzed in accordance with time [6] and occupied field zones [6]); (iii) physical performance during a match (activity profiles and distances covered at various speeds) $[13,14]$; and (iv) frequency and types of players' technical actions [9].

\footnotetext{
*Address correspondence to this author at the Faculty of Human Kinetics, Technical University of Lisbon, Estrada da Costa, 1495-688 Cruz Quebrada, Lisbon, Portugal; Tel.: +351 965220648; Fax: + 351 214144712;

E-mail: jmpratas@fmh.utl.pt
}

Lago, Martin and Seirul-lo [10] observed an inverse relationship between the ranking of opponents and the number of shots made by the F. C. Barcelona team, as well as a direct relationship between the quality of opposition and the shots that team received in thirty-seven Spanish Premier League matches played in the 2004-2005 season. The influence of opponent quality was also verified on the time of ball possession of a professional football team in twenty-seven Spanish Premier League matches played in the 2005-2006 season [6]. For instance, Lago [6] reported that each unit of distance in end-of-season ranking between competing teams increased/decreased the team's possession by $0.2 \%$. No significant effect of opponent quality was identified on the zones occupied by a team during ball possession (defensive, intermediate and offensive zones).

The findings of Rampini, Impellizzeri, Castagna et al. [14] suggested an increase in the physical performance intensity of top-level professional players when playing against stronger opponents. The analysis of the interactive effects of quality of opposition and match location on distance covered at various speeds in elite Spanish football showed that greater distances were covered with low intensity by home teams in comparison with away teams in matches played against stronger opponents [13]. Analysis of team possession based on evolving match status has also confirmed the significant effect of score-line on team offensive strategies. O'Donoghue and Tenga [7], James, Mellalieu and Holley [15], Bloomfield, Polman and O'Donoghue [16] and Lago [6] observed that teams enjoyed longer periods of ball possession when they were losing. Taylor, Mellalieu, James et al. [8] reported that when drawing and losing, the 
British team observed in the case study in question made less successful shots in comparison with when they were winning. An increasing of number of ball interceptions and clearances was also recorded, as well as a decrease in dribbling and passing in winning situations.

Although game period has been suggested as one of the factors that influences team performance [12, 13, 17], studies involving notation analysis have paid relatively little attention to this situational variable. Studies that involved game period analysis have predominantly focused on score evolution during matches. Some researchers that examined whether the number of goals scored was related to game period have reported ambiguous results $[18,19]$. Abt, Dickson and Mummery [20] observed an upward trend in the number of goals scored as time progressed in 703 matches played during four seasons of the Australian National Soccer League. The highest percentage of goals was scored in the last 5-minute period of each half $\left(41^{\mathrm{st}}-45^{\text {th }} \mathrm{min}\right.$. and $86^{\text {th }}-90^{\text {th }}$ min.). Acar, Yapiciolgu, Arikam et al. [21] verified that in 2006 FIFA World Cup matches the greatest number of goals was scored between the $75^{\text {th }}$ and $90^{\text {th }}$ minutes. It was also noted that the frequency and efficacy of shots increased as the match progressed. However, Michailidis, Michailidis, Papaiakovou et al. [18] reported no significant relationship between game period and goals scored in 237 European Champions League of Football during the 2002-2003 season.

The importance of considering the independent and interactive effects of situational variables on the behavioral level of performance in football was demonstrated by Taylor et al. [9]. The authors reported variations of the frequency, types and outcomes of players' technical actions as a function of match location, quality of opposition, and match status, analyzed independently and interactively for forty matches played by a professional British football team in the 2002-03 and 2003-04 seasons [9]. The findings in this case study highlighted the greater impact of match context on the occurrence of certain technical actions rather than on their outcomes. The case study design of this piece of research was described by the authors as more detailed than approaches based on the aggregate data traditionally used in notational analysis in football. According to Taylor et al. [9], the case study allows us to focus on the specific technical and tactical aspects of a team's performance and contributes towards the more precise identification of factors that influence the strengths and weaknesses of a team in different competitive contexts.

Despite the fact that the importance of considering the situational variables on the assessment of tactical and physical performance in football has been highlighted in different studies $[4,6,8,13,14]$ no research has investigated the impact of these variables on the team behavior in the situations that lead to a shot on goal. Furthermore, the literature analyzing this specific question does not include any studies involving the spatial-temporal analysis of player performance in offensive sequences ending in a shot on goal and its relationship with situational variables. The identification of the actions and attitudes that lead to offensive success in different competitive contexts may contribute to a better understanding of the key factors that influence performance in football. This is knowledge which is of crucial importance for guiding a team during a game, and also for organizing the training process in a more efficient way.

Based on existing research, the aim of this case study is to analyze the independent and interactive effects of two situational variables - quality of opposition and game period - on team performance in the offensive sequences ending in a shot on goal in matches played by a professional team in the Portuguese Premier League during the 2009-2010 season.

\section{METHODS}

\section{Match Sample}

A total of 155 offensive sequences ending in a shot on goal were selected from ten matches played by a professional team in the Portuguese Premier League during the 2009-

Table 1. Description of Sampled Matches

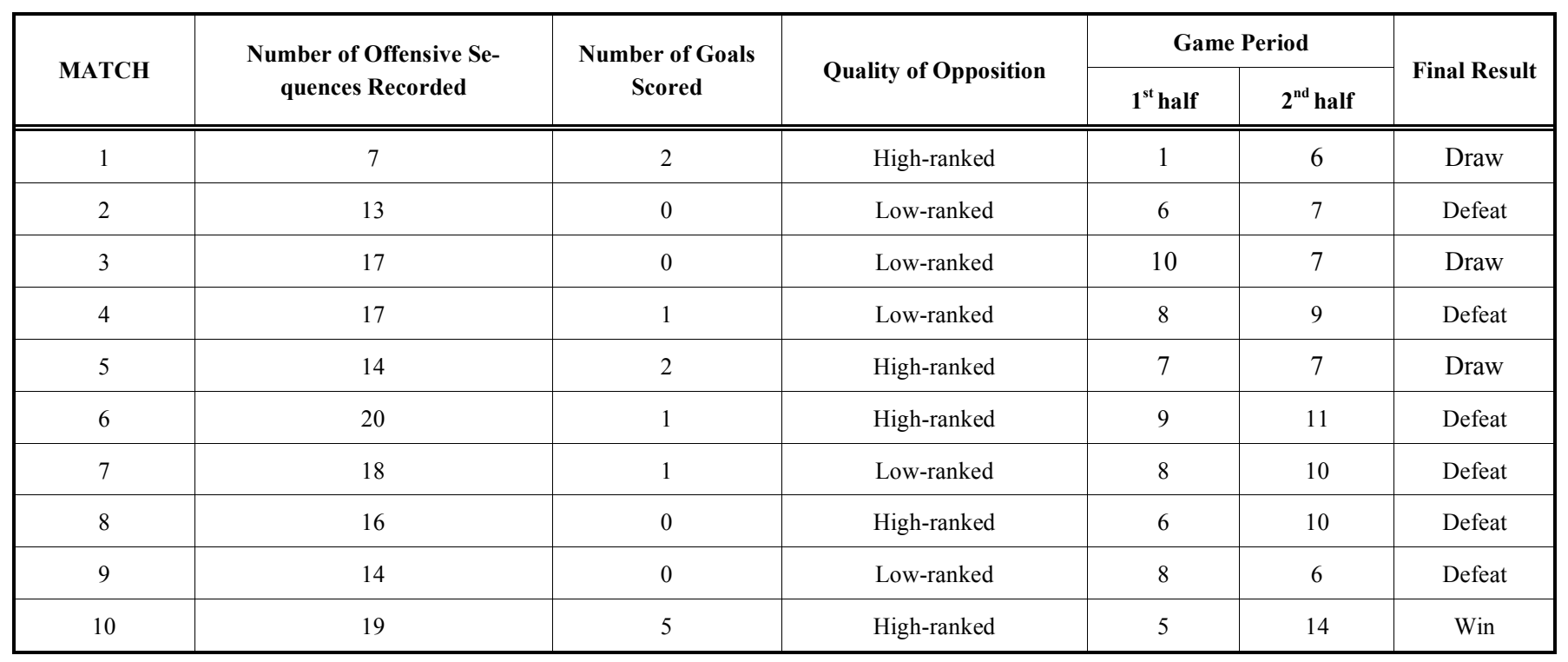


2010 season. All matches were played at home. A detailed description of sampled matches is presented in Table $\mathbf{1}$.

\section{Data Collection Procedures}

Offensive sequences were recorded using two digital HD Sony Model NEX-VG20EH video cameras placed on tripods in an elevated position in the commentator's booth, transverse to the field of play. Each camera was used to film half of the field. Camera zooming rate was fixed in order to simplify motion image processing. Images were edited using Ulead Video Studio version 12.0 software and saved in AVI format.

The study was carried out in two stages. Firstly, an observational system was developed for the recording, quantification and analysis of players' actions during offensive sequences ending in a shot on goal. This system was supported by existing notational analysis literature [21-23] and included performance indicators previously used in football performance analysis research. The system incorporated 14 performance indicators (see Table 2) that were recorded using Match Vision Studio version 1.0 software.

The second stage of the study focused on three spatialtemporal variables describing player behavior in offensive sequences ending in a shot on goal, such as distance covered by the player, distance between players and ball and speed of the ball. Image processing was carried out using TACTO 7.0 software package $[24,25]$. Ball and player trajectories were digitized at $25 \mathrm{~Hz}$, in slow motion, from the start of ball possession until the kicker's foot was in contact with the ball during finalization. The movement coordinates obtained were converted into real coordinates using the direct linear transformation method (2D-DLT) and filtered using a Butterworth low pass filter $(6 \mathrm{~Hz})[26]$. All data were computed using MATLAB software (R2009a, MathWorks, USA), revealing velocity and distances relating to the following performance variables: speed of the ball, distance covered by attackers, and distance between attacking players and the player with ball possession. Data acquisition processes were approved by the university's human research ethics committee and authorized by the club where the present research was developed.

Quality of opposition was determined by the difference between the latest rankings of the team considered and the opponents. A k-means cluster analysis was performed to identify a cut-off value of ranking difference and classify the quality of opposition into two groups: high-ranked opponents (a difference in ranking positions from 8 to 15), and low-ranked opponent (a difference in ranking positions from -1 to 6 ). The game period was classified as first or second half of match.

\section{Reliability Testing}

In the first stage of the study, the reliability (intra- and inter-observer) of the observational system of player offensive actions was measured using the Kappa of Cohen coefficient. For this purpose, $21 \%$ of the sample was analyzed

Table 2. Classes of Performance Indicators Used in the Study

\begin{tabular}{|c|c|}
\hline Performance Indicators & Classes \\
\hline Quality of opposition (QO) & High-ranked opponent (HRO), Low-ranked opponent (LRO) \\
\hline Game period (GP) & First half $\left(1^{\text {st }} \mathrm{H}\right)$ and second half $\left(2^{\text {nd }} \mathrm{H}\right)$ \\
\hline Game situation (GS) & $\begin{array}{l}\text { Free play (FP), Set plays (SP: throw-in, corner kick, indirect free kick, direct free kick, penalty kick } \\
\text { and dropped-ball) }\end{array}$ \\
\hline Ball-possession recovery sector (BPRS) & $\begin{array}{l}\text { Field of play divided into four identical transverse sectors: Defensive sector (DS), defensive midfielder } \\
\text { sector (DMS), offensive midfielder sector (OMS), offensive sector (OS) }\end{array}$ \\
\hline Number of players (NP) & One (1), Two or three (2-3), Four or five (4-5), six or more (6+) \\
\hline Number of field-side changes (NFSC) & $\begin{array}{l}\text { Field of play divided into three identical longitudinal corridors (left corridor, central corridor and right } \\
\text { corridor). Zero (0), One (1), Two (2), Three or more ( } 3+)\end{array}$ \\
\hline Number of passes (NPM) & Zero to three $(0-3)$, Four to six $(4-6)$, Seven and more $(7+)$ \\
\hline Numerical relationship: attack-defense (NRAD) & Numerical superiority (NS), Numerical equality (NE), Numerical inferiority (NI) \\
\hline End of offensive sequence (EOS) & $\begin{array}{l}\text { Positive total success (PTS - goal scored), Positive partial success (PPS - attempt on goal defended by } \\
\text { goalkeeper or ball hit a player or goal posts, without goal being scored), Unsuccessfully positive (UP - } \\
\text { ball went over goal line) }\end{array}$ \\
\hline Shoot area (SA) & $\begin{array}{l}\text { The penalty box is the area in which the goalkeeper may handle the ball. The goal box is the area } \\
\text { from which a goal kick is taken. Goal box (GB), Penalty box (PB), Outside the penalty box (OPB) }\end{array}$ \\
\hline Length of offensive action (LOA) & Zero to five seconds $(0-5)$, Six to eleven seconds $(6-11)$, Twelve or more seconds $(12+)$ \\
\hline Speed of the ball (SB) & Continuous record throughout the offensive sequence \\
\hline Distance covered by players (DCP) & \multirow{2}{*}{$\begin{array}{l}\text { Continuous recording. Average distance of all players who have direct involvement in the offensive } \\
\text { sequence }\end{array}$} \\
\hline Distance of players from the ball (DPB) & \\
\hline
\end{tabular}


twice with a two-week interval [27]. Kappa values ranged from 0.85 to 1 for all variables, that is, above the reference value $(0.75)$, indicated in the literature, thus ensuring a good level of intra-and inter-observer reliability.

In the second stage of the study, the reliability of data related to ball and player trajectories was assessed using technical error of measurement (TEM), relative TEM (\%TEM) and coefficient of reliability (R) statistics, respectively [28]. Seventeen of the total number of offensive sequences subjected to data analysis were randomly selected and ball and attacking-player data trajectories were redigitized by the same experimenter. TEM yielded values of 0.159 meters $(4.0 \%)$ and 0.180 meters $(5.0 \%)$ for players and the ball, respectively. The coefficient of reliability showed a good level of reliability for the data recorded for the players $(\mathrm{R}=0.98)$ and ball $(\mathrm{R}=0.97)$.

\section{Data Analysis}

During the first stage of the study, log-linear modeling was used to analyze the independent and interactive effects of the quality of opposition and game period on the frequency of offensive performance indicators. Following the cross-tabulation of situational and performance variables, the data were examined to ensure that sample size and the size of expected frequencies were in accordance with assumptions made for log-linear modeling. All variables were independent, and the dependent variable was the log of the number of cases in a cell of multiway cross-tabulation. Statistical procedures were carried out using IBM SPSS software for Windows ${ }^{\circledR}$, version 20.0. Starting with the saturated model within hierarchical log-linear analysis, backwards elimination was applied in order to remove non-significant threeway and two-way interactions between variables using a statistical significance cut-off of 0.05 . After this step, parameters were estimated for each main and interaction term retained within the model.

In the second stage of the study, descriptive analyses (mean and standard deviation) were carried out in order to characterize spatial-temporal variables. The normal distribu- tion of the data was verified using the Kolmogorov-Smirnov test and the homogeneity of variances was ensured by carrying out Levene's test. Two-way ANOVA analysis was performed to evaluate the effects of the quality of opposition and game period on spatial-temporal variables (speed of the ball, distance covered by players and distance between the player and the ball) calculated on the basis of player and ball coordinates.

\section{RESULTS}

Log-linear modeling did not show any significant interactive effect of the situational variables (quality opposition*game period) on performance indicators in the offensive sequences ending in a shot on goal. The main effect of the quality of opposition was verified on game situation and numerical relationship: attack-defense and a significant main effect was found for game period only on the length of offensive actions (see Table 3). Other performance indicators (ball-possession recovery sector, number of players, number of field side changes, number of passes, end of offensive sequence and shoot area) did not show any situational variables effect. For these indicators, models consisted of a constant, and parameters related to situational variables were not estimated.

Using the parameters estimated (see Table 4), when the team played against high-ranked opposition a significantly higher number of shots were made from a free play situation rather than from set play (for example, throw-in, corner kick, indirect free kick, direct free kick, penalty kick, droppedball). In matches against stronger opposition, the team made a significantly higher number of shots when in a position of numerical equality or superiority. In the first half of match, the team made significantly fewer shots in offensive sequences with a duration of six to eleven seconds, in comparison with the second half.

Two-way ANOVA analysis did not reveal any significant interactive effects of quality of opposition or game period on the spatial-temporal variables that were used to describe player behavior in offensive sequences ending in a shot on

Table 3. Effects of Situational Variables on Performance Indicators

\begin{tabular}{|c|c|c|c|c|}
\hline Performance indicators & Model $^{1}$ & Likelihood ratio $X^{2}$ & d.f. & $P^{2}$ \\
\hline Length of offensive action & {$[\mathrm{GP}]$} & 3.838 & 5 & 0.573 \\
\hline Ball-possession recovery sector & Constant only ${ }^{3}$ & 2879 & 2 & 237 \\
\hline Number of field-side changes & Constant only ${ }^{3}$ & 3,689 & 0 & 0.297 \\
\hline Number of passes & Constant only ${ }^{3}$ & 0.000 & 0 & --- \\
\hline End of the offensive sequence & Constant only ${ }^{3}$ & 0.000 & 0 & --- \\
\hline Shoot area & Constant only ${ }^{3}$ & 0.000 & 0 & --- \\
\hline
\end{tabular}

${ }^{1}$ Situational variables included in the model are shown in square brackets.

${ }^{2} \mathrm{P}$-values indicate whether the model of best-fit was significantly different from the full model.

${ }^{3}$ Constant only models do not retain any effects of situational variables. 
Table 4. Parameter Estimates for the Frequency of the Offensive Performance Variables Performed by a Portuguese Professional Football Team, as a Function of Quality of Opposition [QO] and Game Period [GP]

\begin{tabular}{|c|c|c|c|}
\hline Constant & 15.528 & 26430 & 5.532 \\
\hline$[\mathrm{QO}=$ High-ranked opponent $] \times[\mathrm{GS}=$ Set plays $]$ & $-2.483 *$ & & \\
\hline$[\mathrm{QO}=$ High-ranked opponent $] \times[\mathrm{GS}=$ Free play $]$ & - & & \\
\hline$[\mathrm{QO}=$ Low-ranked opponent $] \times[\mathrm{GS}=$ Free play $]$ & - & & \\
\hline $\begin{array}{l}\text { [QO = High-ranked opponent }] \times[\mathrm{NRAD}=\text { Numerical superior- } \\
\text { ity }]\end{array}$ & & $2.086^{*}$ & \\
\hline$[\mathrm{QO}=$ High-ranked opponent $] \times[\mathrm{NRAD}=$ Numerical equality $]$ & & $2.435^{*}$ & \\
\hline$[\mathrm{QO}=$ Low-ranked opponent $] \times[\mathrm{NRAD}=$ Numerical equality $]$ & & - & \\
\hline$[\mathrm{QO}=$ Low-ranked opponent $] \times[\mathrm{NRAD}=$ Numerical inferiority $]$ & & - & \\
\hline$\left[\mathrm{GP}=1^{\text {st }}\right.$ half $] \times[\mathrm{LOA}=0-5$ seconds $]$ & & & - \\
\hline$\left[\mathrm{GP}=1^{\mathrm{st}}\right.$ half $] \mathrm{x}[\mathrm{LOA}=6-11$ seconds $]$ & & & $-3.244 *$ \\
\hline$\left[\mathrm{GP}=1^{\mathrm{st}}\right.$ half $] \times[\mathrm{LOA}=12$ or more seconds $]$ & & & - \\
\hline$\left[\mathrm{GP}=2^{\mathrm{st}}\right.$ half $] \times[\mathrm{LOA}=0-5$ seconds $]$ & & & - \\
\hline$\left[\mathrm{GP}=2^{\text {st }}\right.$ half $] \times[\mathrm{LOA}=6-11$ seconds $]$ & & & - \\
\hline$\left[\mathrm{GP}=2^{\text {st }}\right.$ half $] \times[\mathrm{LOA}=12$ or more seconds $]$ & & & - \\
\hline
\end{tabular}

$* \mathrm{z}>1.96$ model effect represents a significant change $(P<0.05)$ in performance variables from the model constant.

- = effect not present in the model.

goal. There was a significant main effect of quality of opposition on speed of the ball $(\mathrm{p} \leq 0.05)$. In matches against high-ranked and low-ranked opponents, the average speed of the ball was significantly higher (see Table 5). There was no significantly difference between matches played against highranked and low-ranked opponents for distance covered by players and distance of players from the ball. The distances covered by players in offensive sequences ending in a shot on goal during the first and second half were significantly different $(\mathrm{p} \leq 0.05)$. No significant main effect of game period was observed on speed of the ball and distance of players from the ball in offensive sequences ending in a shot on goal.

\section{DISCUSSION}

The aim of this study is to identify the independent and interactive effects of two situational variables (quality of opposition and game period) on team performance in offensive sequences ending in a shot on goal in matches involving a Portuguese professional football team.

Our findings do not completely support suggestions made in previous studies that emphasized the significant interactive effects of situational variables of team performance in elite football $[6,16]$. The results of this study point only to an independent effect of quality of opposition and game pe-

Table 5. Effect of the Quality of Opposition and Game Period on Spatial-temporal Variables (mean $\pm s d)$

\begin{tabular}{|c|c|c|c|}
\hline & Speed of the Ball $\left(\mathbf{m} / \mathbf{s}^{-1}\right)$ & Distance Covered by the Players (m) & Distance of the Players to the Ball (m) \\
\hline \hline High-ranked opponents & $3,92 \pm 1,64^{*}$ & $24,4 \pm 6,01$ & $17,18 \pm 5,79$ \\
\hline Low-ranked opponents & $3.18 \pm 1.39^{*}$ & $27.49 \pm 9.75$ & $17.18 \pm 4.93$ \\
\hline First half & $3.29 \pm 1.6$ & $28.18 \pm 9.03^{\#}$ & $18.20 \pm 6.56$ \\
\hline Second half & $3.79 \pm 1.5$ & $24.07 \pm 6.86^{\#}$ & $16.41 \pm 4.16$ \\
\hline
\end{tabular}

* Significant difference $(\mathrm{p} \leq 0.05)$ between high- and low-ranked opponents;

${ }^{\#}$ Significant difference between $1^{\text {st }}$ and $2^{\text {nd }}$ halves $(\mathrm{p} \leq 0.05)$. 
riod on offensive team performance, which could be explained by case design and the small number of situational variables considered in the analysis.

For example, the small number of shots made from set plays when the team played against stronger opponents could indicate better performance of the observed team in open play or resulted from the good defensive organization of high-ranked teams, which do not allow their opponents many opportunities for making shots as a result of set plays (e.g. corner-kicks, free kicks, penalties and throw-ins).

These results differ from the findings of Taylor et al. [9] that reported no significant effect of situational variables on the incidence of behaviors related to set plays. According to Acar et al. [21], Armatas et al. [17], Grant, Williams and Reilly [29] and Kirkendall, Dowd and DiCicco [30] in modern elite football $29-37 \%$ of goals are scored as a consequence of set plays such as corner-kicks, penalties, freekicks and throw-ins. Thus, further research should distinguish between different game situations (open play $v s$ set plays) in order to make analysis more precise and more useful for coaches and sport analysts $[4,9]$.

Our data suggest that the numerical superiority or equality of the offensive team when playing against strong opponents is an important factor influencing the creation of opportunities for shooting. Therefore, the assessment of opponent interactions is crucial to evaluate the effectiveness of offensive actions and improve the validity of performance analysis [31].

The significant effect of game period on the length of offensive actions indicates that teams perform significantly fewer direct plays (offensive sequences with a duration of six to eleven seconds) in the first half of matches. One reason could be that players consider rapid movements with the ball to involve risk and are therefore attempt less such actions during the first half, when the match result is not yet decided [12]. In order to obtain more reliable results regarding the effect of game period on team performance, in future analyses, splitting of game time into shorter time intervals (for example, six periods of fifteen minutes each or the specific time period since the last change of match status) should be considered $[9,20]$.

The novelty of this study was to analyze the spatialtemporal variables that characterize the offensive teams' performance according to the match context. One of the most important requirements for the creation of shooting opportunities is the high speed of ball movement and player movement in areas close to the goal of the opposing team [21]. The results of spatial-temporal analysis suggest that a stronger opposition obliges the offensive team to act faster in order to create shooting opportunities. However, the team did not cover greater distances in sequences ending in a shot on goal. Our results are similar to the findings reported by Rampini, Impellizzeri, Castagna et al. [14], who examined the influence of situational variables on the match performance of top-level footballers and found that their performance was influenced by the activity profile of the opposing team. The level of intensity of displacement during matches was higher when teams played against stronger opponents.
The analysis of the average distance covered by players during offensive sequences ending in a shot on goal did not demonstrate significant differences regarding quality of opposition. These results contradict the findings of some authors [13, 32] who recorded greater distances covered by players in matches played against better teams. This discrepancy may be explained by differences in data collection. In the present study, the distance covered by players was recorded only for offensive sequences ending in a shot on goal, and not for the total distance covered by players during matches $[13,32]$.

In accordance with our findings, in the second half of matches players covered shorter distances in the sequences ending in a shot on goal as compared with the first half. Several studies have reported a decrease in physical performance in the second half of matches. Some of them have explained this due to physical fatigue [14, 33-35], but recent research $[13,36]$ has shown that match location, quality of opposition and match status also influence player activity during matches. For instance, Carling [12] reported that total distance run did not differ between halves but varied over the course of matches, decreasing just before half-time. This result suggests that distance covered is not affected by gamerelated fatigue. Di Salvo, Gregson, Atkinson et al. [36] demonstrated that positional differences in high-intensity activity as well as the observed change in activity throughout the game were influenced by team success $(\mathrm{p}<0.05)$.

Differences in style of play depend on the characteristics of the team and the opponents, and are influenced by team strategy selected for a given match. Lack of data regarding match status variable did not allow for the inclusion of scoreline in our analysis, but this information is essential for an understanding of a team's tactical options in terms of ball management.

\section{CONCLUSION}

Our main findings indicate that team strategies in the creation of shooting opportunities are influenced by the quality of opposition and game period. These variables demonstrate only independent effects on team offensive performance, revealing several changes in team strategy as a response to the specific match situation. Although the offensive patterns observed in this study refer to one particular team, our findings may contribute towards providing a better understanding the behavior of elite footballers in offensive sequences ending in a shot on goal in different match contexts, and thus may help coaches to organize training processes in accordance with the demands of specific competition situations.

Further research should consider the effect of match location and score-line on team offensive performance involving ball possessions ending in a shot on goal. A more substantial research effort is needed for the spatial-temporal analysis of player performance in different game situations, also taking into account defense activity.

\section{CONFLICT OF INTEREST}

The authors confirm that this article content has no conflicts of interest. 


\section{ACKNOWLEDGEMENTS}

None declared.

\section{REFERENCES}

[1] Hughes MD, Churchill S. Attacking profiles of successful and unsuccessful team in Copa America 2001. In: Reilly T, Cabri J, Araújo D, Eds. Science and Football V. London and New York: Routledge 2005; pp. 219-24.

[2] Hughes MD, Franks I. Analysis of passing sequences, shots and goals in soccer. J Sports Sci 2005; 23(5): 509-14.

[3] Jones PD, James N, Mellalieu D. Possession as a performance indicator in soccer. Int J Perform Anal Sport 2004; 4: 98-102.

[4] CarlingC, WilliamsAM, ReillyT. Handbook of soccer match analysis: a systematic approach to improving performance. Abingdon, UK: Routledge 2005.

[5] Bar-Eli M, Tenenbaum G, Geister S. Consequences of players dismissal in professional soccer: a crisis-related analysis of groupsize effects. J Sports Sci 2006; 24(10): 1083-94.

[6] Lago C. The influence of match location, quality of opposition and match status on possession strategies in professional association football. J Sports Sci 2009; 27(13): 1463-9.

[7] O'Donoghue PG, Tenga A. The effect of score-line on work rate in elite soccer. J Sports Sci 2001; 19: 25-6.

[8] Taylor JB, Mellalieu SD, James N. Behavioural comparisons of positional demands in professional soccer. Int J Perform Anal Sport 2004; 4: 81-97.

[9] Taylor JB, Mellalieu SD, James N, Sheraer D. The influence of match location, quality of opposition and match status on technical performance in professional association football. J Sports Sci 2008; 26(9): 885-95.

[10] Lago C, Martín Acero R, Seirul-lo F. El rendimiento en el fútbol. Una modelización de las variables determinantes para el F.C. Barcelona. Apunts 2007; 90: 51-8.

[11] Lago C, Dellal A. Ball Possession Strategies in Elite Soccer According to the Evolution of the Match - Score: the Influence of Situational Variables. J Hum Kinet 2010; 25: 93-100.

[12] Carling C. Analysis of physical activity profiles when running with the ball in a professional soccer team. J Sports Sci 2010; 28(3): 319-26.

[13] Lago C, Casais L, Dominguez E, Sampaio J. The effects of situational variables on distance covered at various speed in elite soccer. Eur J Sport Sci 2010; 10: 103-9.

[14] Rampinini E, Impellizzeri FM, Castagna C, Coutts AJ, Wisløff U. Technical performance during soccer matches of the Italian Serie A league: effect of fatigue and competitive level. J Sci Med Sport 2009; 12: 227-33.

[15] James N, Mellalieu SD, Holley C. Analysis of strategies in soccer as a function of European and domestic competition. Int J Perform Anal Sport 2002; 2: 85-103.

[16] Bloomfield JR, Polman RCJ, O'Donoghue PG. Effects of scoreline on team strategies in FA Premier League Soccer. J Sports Sci 2005; 23: 192-3.

[17] Armatas V, Yiannakos A, Sileloglou P. Relationship between time and goal scoring in soccer games: analysis of three world cups. Int J Perform Anal Sport 2007; 7(2): 48-58.
[18] Michailidis C, Michailidis I, Papaiakovou G, Papaiakovou I. Analysis and evaluation of way and place that goals were achieved during the European Champions League of Football 2002-2003. Sports Organiz 2004; 2(1): 48-54.

[19] Yiannakos A, Armatas V. Evaluation of the goal scoring patterns in European Championship in Portugal 2004. Int J Perform Anal Sport 2006; 6(1): 178-88.

[20] Abt GA, Dickson G, Mummery WK. Goal scoring patterns over the course of a match: an analysis of the Australian National Soccer League. In: Spinks W, Reilly T, Murphy A, Eds. Science and Football IV. London: Routledge 2002; pp. 107-11.

[21] Acar M, Yapiciolgu B, Arikam N, Yalcin S, Ates N, Ergun M. Analysis of goals scored in the 2006 World Cup. In: Reilly T, Korkusuz F, Eds. Science and Football VI. London and New York: Routledge 2009; pp. 235- 42.

[22] Hughes MD, Bartlett R. The use of performance indicators in performance analysis. J Sports Sci 2002; 20: 739-54.

[23] Martinez L, Lago-Ballesteros J. Analysis of offensive playing patterns in soccer. J Sports Sci 2007; (Suppl. 10): 199-209.

[24] Duarte R, Araújo D, Fernandes O, et al. Capturing complex human behaviors in representative sports contexts with a single camera. Medicina(Kaunas) 2010; 46(6): 408-14.

[25] Fernandes O, Malta P. Techno-tactics and running distance analysis using one camera. J Sports Sci Med 2007; 6(Suppl.10): 204-5.

[26] Winter D. Biomechanics and motor control of human movement $3^{\text {rd }}$ ed. New York: John Wiley \& Sons 2005.

[27] Tabachnick B, Fidell L. Using multivariate statistics. New York: Harper \& Row Publishers 1989.

[28] Goto R, Mascie-Taylor CGN. Precision of measurement as a component of human variation. J Physiol Anthropol 2007; 26(2): 253-6.

[29] GrantAG, Williams AM, Reilly T. An analysis of the successful and unsuccessful teams in the 1998 World Cup. J Sports Sci 1999; 17: 827 .

[30] Kirkendall D, Dowd W, DiCicco A. Patterns of successful attacks: a comparison of the men's and women's World Cup. Rev Fútbol Cienc 2002; 1 (1).

[31] Tenga A, Holme I, Ronglan LT, Bahr R. Effect of playing tactics on goal scoring in Norwegian professional soccer. J Sports Sci 2010; 28(3): 237-44.

[32] Castellano J, Blanco-Villaseñor A, Álvarez D. Contextual variables and time-motion analysis in soccer. Int J Sports Med 2011; 32(6): 415-21.

[33] Barros RML, Misuta MS, Menezes RP, et al. Analysis of the distances covered by first division Brazilian soccer players obtained with an automatic tracking method. J Sports Sci Med 2007; 6: 23342.

[34] Mohr M, Krustrup P, Bangsbo J. Fatigue in soccer: a brief review. J Sports Sci 2005; 23: 593-9.

[35] Rampinini E, Coutts AJ, Castagna C, Sassi R, Impellizzeri FM. Variation in top-level soccer match performance. Int J Sports Med 2007; 28: 1018-24.

[36] Di Salvo V, Gregson W, Atkinson G, Tordoff P, Drust B. Analysis of high intensity activity in Premier League soccer. Int J Sports Med 2009; 30: 205-12.

Received: January 18, 2012

Revised: June 20, 2012

Accepted: June 21, 2012

(C) Pratas et al.; Licensee Bentham Open.

This is an open access article licensed under the terms of the Creative Commons Attribution Non-Commercial License (http://creativecommons.org/licenses/ by-nc/3.0/) which permits unrestricted, non-commercial use, distribution and reproduction in any medium, provided the work is properly cited. 